\title{
Implementasi Strategi KPP Pratama Surakarta dalam Meningkatkan Pengguna E-filing di Kota Surakarta
}

\section{Implementing the Strategy of Increasing the E-filling User Number in KPP Pratama Surakarta}

\author{
Rino Ardhian Nugroho, Christoper Danesh Abraham \\ Program Studi Ilmu Administrasi Negara \\ Fakultas Ilmu Sosial dan Politik, Universitas Sebelas Maret Surakarta \\ rino.nugroho@staff.uns.ac.id
}

\begin{abstract}
Abstrak
Penelitian ini berkaitan tentang implementasi strategi yang dilakukan oleh KPP Pratama Surakarta yang bertujuan untuk meningkatkan pengguna e-filling di Kota Surakarta. Direktorat Jendral Pajak telah menetapkan rencana strategis yaitu migrasi wajib pajak untuk beralih menggunakan $e$-filling. Dalam pelaksanaan atau implementasinya di tingkat kota Surakarta, KPP Pratama Surakarta diwajibkan untuk mensukseskan migrasi tersebut. Jika dilihat dari tujuannya, penelitian ini bersifat deskriptif.Adapun teknik pengumpulan data yang digunakan pada penelitian ini adalah wawancara dan dokumentasi.Sedangkan untuk penentuan informan, peneliti menggunakan purposive sampling, dan validitas data dilakukan menggunakan triangulasi data.Selanjutnya untuk menganalisis data yang diperoleh, peneliti menggunakan model analisis interaktif dari HB Sutopo.penelitian ini menunjukkan bahwa, implementasi strategi KPP Pratama Surakarta untuk meningkatkan pengguna e-filling di Kota Surakarta, diutamakan pada kegiatan sosialisasi demi mensukseskan migrasi wajib pajak dan mencapai target sebesar 65\%. Adapun kegiatan sosialisasi yang dilakukan dibedakan menjadi dua jenis, secara langsung maupun tidak langsung. Anggaran yang digunakan oleh KPP Pratama Surakarta telah ditetapkan oleh Direktorat Jendral Pajak. Anggaran tersebut dapat diubah dengan caraswitch change sesuai kebutuhan. Dalam pelaksanaan prosedurnya, KPP Pratama Surakarta lebih mengutamakan turun langsung kedaerah kantong-kantong wajib pajak sesuai perintah kepala KPP Pratama Surakarta.Sedangkan aspek sosial, KPP Pratama Surakarta telah menyediakan sekitar 20 komputer yang terhubung intrnet dan menyediakan pembimbing untuk melayani wajib pajak untuk melakukan pengisian form e-filling secara online.
\end{abstract}

Kata Kunci: E-filling, Migrasi wajib pajak, Implementasi Strategi

\begin{abstract}
This research discussed the implementation of strategy taken by KPP Pratama Surakarta aiming to increase the number of e-filling users in Surakarta City. Tax Directorate General has determined a strategic plan, that is, taxpayer migration to switch to using e-filling. In its implementation at Surakarta City level, KPP Pratama Surakarta is obliged to make the migration
\end{abstract}


successful. Viewed from its objective, this research was descriptive in nature. Techniques of collecting data used in this research were interview and documentation. Meanwhile, to select informant, the author employed purposive sampling, and data validation was carried out using data triangulation. Furthermore to analyze the data obtained, the author employed an interactive model of analysis from HB Sutopo. The result of research showed that the implementation of KPP Pratama Surakarta's strategy of increasing the number of e-filling users in Surakarta City, particularly in socialization activity in order to make the taxpayer migration successful and to achieve target of $65 \%$. Meanwhile, the socialization activity conducted was distinguished into two types: direct and indirect. The budget used by KPP Pratama had been determined by Tax Directorate General. The budget could be changed using switch change method if necessary. In its procedure implementation, KPP Pratama Surakarta emphasizes on going directly into taxpayer pouches corresponding to KPP Pratama Surakarta Chairperson's command. Meanwhile, in social aspect, KPP Pratama Surakarta has provided about 20 computers connected to internet and facilitators to cater to taxpayers in completing e-filling form online.

Keywords: E-filling, taxpayer migration, strategy implementation

\section{A. Pendahuluan}

Pelayanan publik harus berasaskan kepentingan umum, kepastian hukum, kesamaan hak, keseimbangan hak dan kewajiban, profesional, partisipatif, tidak diskriminatif, terbuka, akuntabel, tepat waktu, cepat, mudah, dan terjangkau sesuai

pada Undang-undang Nomer 25 Tahun 2009 tentang Pelayanan Publik. Masyarakat berhak mengetahui kebenaran isi, mengawasi pelaksanaan, mendapatkan tanggapan atas pengaduan, mendapatkan pemenuhan pelayanan, mendapatkan pelayanan yang berkualitas.Pelayanan publik yang berkualitas merupakan salah satu tujuan meningkatkan kesadaran masyarakat dalam melaksanakan tanggung jawabnya, misalnya dalam pembayaran pajak. dilakukan penyempurnaan hingga muncul Peraturan Direktur Jenderal Pajak, Nomor PER-1/PJ/2014 tentang Tata Cara Penyampaian Surat Pemberitahuan Tahunan bagi Wajib Pajak Orang Pribadi yang menggunakan Formulir 1770S atau 1770SS secara e-filing. E-filling adalah penyempuran dari E-SPT dan merupakan sarana pelaporan pajak secara online dan realtime menggunakan media internet dengan melalui penyedia layanan aplikasi atau Application Service Provider.E-filling juga membantu karena ada media pendukung dari Penyedia Jasa Aplikasi (ASP) yang akan membantu dalam 24 jam sehari dan 7 hari dalam seminggu. Dengan begitu, sistem e-filling ini dirasa lebih efektif dan efisien.

Berdasar data Direktorat Jenderal Pajak (Ditjen Pajak), jumlah total pelapor SPT hingga 30 April 2016 adalah 11.674.340. Perinciannya, 11.125.281 orang dan 549.059 wajib pajak badan. Jumlah itu naik 13,1 persen bila dibandingkan dengan 30 April 2015 yang sebanyak 10,3 juta pelapor. Perinciannya, 9.778.708 orang wajib pajak pribadi dan 543.092 WP badan. 
Potensi pengguna e-filling di Kota Surakarta hingga tahun 2015 mencapai sekitar 40.000 wajib pajak orang pribadi, sedangkan target yang ditetapkan untuk KPP Pratama Surakarta sekitar 26.000 atau $65 \%$ dari potensi WP OP yang diharapkan melapor di KPP Pratama Surakarta menggunakan $e$ filling.

\section{B. Tinjauan Pustaka \\ a. Implementasi Strategi}

Implementasi strategi menurut Hunger dan Wheelen merupakan proses yang menentukan dimana manajemen mewujudkan strategi dan kebijakannya, yang dalam tindakannya dibagi melalui pengembangan program, anggaran, dan prosedur.

1. Program. Program merupakan pernyataan aktivitas-aktivitas atau langkah-langkah yang diperlukan untuk menyelesaikan perencanaan sekali pakai. Program melibatkan restrukturisasi perusahaan, perubahan budaya internal perusahaan, atau awal dari suatu usaha penelitian baru.

2. Anggaran. Anggaran yaitu program yang dinyatakan dalam bentuk satuan uang atau modal, yang setiap program akan dinyatakan secara rinci dalam biaya, yang dapat digunakan oleh manajemen untuk merencanakan dan mengendalikan setiap program yang dilaksanakan.

3. Prosedur. Prosedur adalah sistem langkah-langkah penting atau teknik yang berurutan yang menggambarkan secara rinci bagaimana suatu tugas atau pekerjaan diselesaikan.
Dari penjabaran mengenai implementasi di atas dapat disimpulkan bahwa implentasi merupakan suatu proses yang mana proses tersebut terdiri dari tindakan yang di kemas dalam bentuk program atau kegiatankegiatan yang telah dirumuskan sebelumnya dalam tahapan perumusan kebijakan atau perumusan strategi. Implementasi merupakan tindakan yang sangat menentukan keberhasilan sebuah rencana atau misi yang telah dibuat sebelumnya tanpa implementasi rencana hanya akan jadi angan-angan semu.

Sedangkan implementasi strategi, menurut Higgins dalam Salusu (1996: 409) menyatakan bahwa implementasi yaitu rangkuman dari berbagai kegiatan yang didalamnya sumber daya manusia menggunakan sumber daya lain untuk mencapai sasaran dari strategi. Van Meter dan Van Horn dalam Subarsono (2005: 99) mengemukakan variable yang mempengaruhi kinerja implementasi strategi:

1. Standard dan Sasaran kebijakan

2. Sumber daya

3. Komunikasi agen pelaksana

4. Kondisi sosisal, ekonomi dan politik

5. Disposisi implementor

\section{b. E-Government}

Clay G. Wescott mendefinisikan $e$ government sebagai berikut dalam Indrajit (2002:4):

E-government is the use of information and communications technology (ICT) to promote more efficient and costeffective government, facilitate more convenient government services, allow 
greater public access to information, and make government more accountable to citizens.

Manfaat-manfaat dari diterapkannya $e$ government menurut Rahardjo (2001:24) adanya servis yang lebih baik kepada masyarakat, peningkatan hubungan antara pemerintah, pelaku bisnis, dan masyarakat umum, terciptanya keterbukaan (transparansi), pemberdayaan masyarakat melalui informasi yang mudah diperoleh, terciptanya pelaksanaan pemerintahan yang lebih efisien. Tipe relasi E-Government, ada 4 (empat) jenis klasifikasi :

1. Government to Citizens $(G 2 C)$, yaitu membangun dan menerapkan berbagai portofolio teknologi informasi untuk memperbaiki hubungan interaksi dengan masyarakat (rakyat).

2. Government to Business $(G 2 B)$, membentuk sebuah lingkungan bisnis yang kondusif.

3. Government to Governments $(G 2 G)$, kebutuhan untuk berinteraksi antar satu pemerintah dengan pemerintah.

\section{Government to Employees $(G 2 E)$,} meningkatkan kinerja dan kesejahteraan para pegawai negeri atau karyawan pemerintahan.

Implementasi E-Government Al-Shafi (2009) mengemukakan bahwa terdapat berbagai faktor yang dapat mempengaruhi implementasi e-government.Faktor-faktor tersebut secara umum dapat diklasifikasikan ke dalam bidang-bidang besar, yaitu organisasi, teknik, politik dan sosial yang didasarkan atas pemahaman bahwa keempat bidang tersebut realitanya mengelilingi sebuah lingkungan implementasi $e$ - government. Keempat bidang tersebut diuraikan sebagai berikut :

1. Bidang Organisasi

Struktur Organisasi E-government, berkaitan dengan alokasi peran kerja dan mekanisme administratif yang membentuk suatu pola hubungan yang memungkinkan sebuah organisasi untuk melakukan, mengkoordinasikan, dan mengendalikan kegiatan kerja. Perlu adanya juga bentuk distribusi kekuasaan, karena e-government menyebabkan peralihan sistem kerja dari manual ke elektronik yang dapat memunculkan hambatan dari sisi staf internal organisasi tersebut.Penetuan arah strategi E-government berkaitan dengan strategi yang memanfaatkan keunggulan sistem informasi dan dukungan teknologi informasi untuk mendukung pemerintahan, memberikan keunggulan, mencapai efektivitas dan efisiensi penyampaian layanan publik. Prioritas penyampaian $E$ Government yaitu penentuan prioritas dititikkan pada manfaat yang bisa dihadirkan.Prioritas dibuat agar pelayanan ditangani dan disampaikan dengan tepat. Karena kebutuhan masa depan $E$ Government, proyek e-government merupakan inisiatif jangka panjang yang memerlukan waktu dan model yang sesuai untuk mendukung implementasi dan pencapaian tujuan organisasi. Budaya Organisasi, peralihan budaya organisasi dari manual ke berbasis teknologi memungkinkan munculnya hambatan oleh karena itu perlu adanya pelatihan staf, pemberian pendidikan dan pelatihan tentang teknologi kepada staf untuk menunjang kerja sama, maka penarikan jasa konsultan 
dan para ahli di bidang Teknologi Informasi menjadi sangat penting.

2. Bidang Teknik

Standar Teknologi Informasi, digunakan untuk mengatasi hambatan-hambatan pada perangkat keras dan sistem yang memungkinkan kegagalan implementasi $e$ government. Perlu adanya keamanan dan kerahasiaan, karena pengawasan berlanjut pada keamanan dan privasi data berdampak pada kepercayaan masyarakat sehingga integrasi sistem, penggabungan sistem informasi antara atasan-bawahan (vertikal), dan antar pemerintahan (horizontal) untuk pelayanan online yang bersatu dan efektif. Portal dan Akses E-Government, ketersedian portal dan akses online 24 jam sehari dan 7 hari seminggu, yang dinamis, aman, dan dapat diakses di mana saja. Pentingnya kemampuan para staf terkait Teknologi Informasi, termasuk juga ketepatan penempatan jabatan sesuai dengan keahliannya. Arah Bisnis dan Teknologi Informasi, arah perkembangan bisnis dan Teknologi Informasi harus mendukung dan tidak berlawanan dengan tujuan pemerintah dalam penyelenggaraan e-government. Sehingga mitra industri lokal, berpengaruh pada keberlanjutan implementasi $e$ government sekaligus menjaga stabilitas lokal pada suaru wilayah.

3. Bidang Sosial

Fokus pada Warga Negara, kebutuhan dan kualitas pelayanan yang diberikan kepada warga negara/masyarakat merupakan fokus dari tujuan implementasi e-government. Tetapi rendahnya kesadaran mempengaruhi tingkat partisipasi maka dapat diupayakan melalui sosialisasi. Kesenjangan Digital juga berkaitan dengan pengetahuan yang dimiliki pihak terkait pelaksana e-government dan kesenjangan antara yang mengerti teknologi dengan yang tidak. Pelatihan dan pendidikan E-Government untuk masyarakat, pendidikan dan pelatihan lebih diutamakan berfokus pada Teknologi Informasi dan Komunikasi secara umum.

4. Bidang Politik

Dukungan Pemerintah diwujudkan melalui komitmen pemerintah untuk melaksanakan e-government dari awal hingga akhir.Keuangan dan Pendanaan dalam implementasi e-government seperti bangunan/gedung, teknologi, dan sumber daya manusia.Kepemimpinan, komitmen dan kemampuan staf pemerintah dalam menemukan inovasi.Legislasi dan Sah, Implementasi e-government memerlukan legalitas yang diwujudkan dengan peraturan perundang-undangan yang mengatur kegiatan dalam praktek e-government. Kecepatan pembangunan dan perubahan pada sektor publik, pembangunan dan perubahan di pemerintahan yang cepat berdampak pada perubahan kebijakan, prosedur, dan kepemilikan bisnis.

\section{c. E-filing}

Secara etimologi e-filing terdiri dari dua kata, yaitu: $e$ untuk electronic dan filing. Electronic berarti penggunaan sistem komputerisasi, sedangkan filing berarti pengisian formulir.Jadi e-filing merupakan sistem terkomputerisasi yang membantu pengisian atau penyampaian SPT tahunan.

Menurut Pasal 1 ayat (6) Peraturan Direktur Jenderal Pajak, Nomor PER-1/PJ/2014 tentang Tata Cara Penyampaian Surat Pemberitahuan Tahunan bagi Wajib Pajak 
Orang Pribadi yang menggunakan Formulir 1770S atau 1770SS secara e-filing melalui website Direktorat Jenderal Pajak mendefinisikan $e$-filing sebagai berikut:

"E-filing adalah suatu cara penyampaian SPT atau penyampaian Pemberitahuan Perpanjangan SPT Tahunan secara elektronik yang dilakukan secara online yang real time melalui website Direktorat Jenderal Pajak dengan alamat www.pajak.go.id".

\section{Metode Penelitian}

Jenis penelitian yang digunakan adalah penelitian deskriptif dengan pendekatan kualitatif. Penentuan informan dalam penelitian ini menggunakan teknik purposive sampling, yaitu dipilih dengan pertimbangan informan mengetahui data yang dibutuhkan. Metode pengumpulan data melalui wawancara dan studi dokumentasi. Pemeriksaaan keabsahan data pada penelitian ini digunakan triangulasi sumber, teknik analisis menggunakan teknik analisis interaktif. Analisis ini terdiri dari tiga alur yaitu: (a) reduksi data, yang diartikan sebagai proses pemilihan, pemusatan perhatian pada penyederhanaan data yang didapat dari lapangan, (b) penyajian data dilakukan dengan menggunakan bentuk teks narasi deskriptif, (c) verifikasi atau penarikan kesimpulan.

\section{Pembahasan}

\section{a. Profil Responden}

Pada penulisan penelitian menggunakan kode dilakukan untuk menjaga kerahasiaan informan sehingga dalam penyampaian informasi akan tetap terjaga kerahasiaannya.
Penelitian ini pertama-tama mengirimkankan surat ijin penelitian ke Kantor Pelayanan Pajak Pratama Surakarta, surat tersebut ditujukan kepada kepala kantor pajak. Setelah mendapatkan ijin penelitian, peneliti langsung menuju ke pihak yang paham tentang program $e$-filing yang berada di KPP Pratama Surakarta. Lalu mencari responden lain sesuai arahan dari salah satu kepala seksi tersebut, dan akhirnya terkumpul informasi dari 4 responden yang mana menjabat sebagai kepala seksi dari bidang yang berberda-beda. Hal ini dimaksudkan supaya informasi yang diberikan lebih sepesifik dan mendalam terkait sehingga dalam pengumupalan data, pilihan informan dapat berkembang pada penelitian ini. KPP1 dianggap telah mengetahui data informasi dan memahami system yang dimiliki oleh Kantor Pelayanan Pajak Pratama Surakarta sehingga data yang diperoleh valid dalam melakukan penggalian informasi.Selain hal tersebut informan merupakan kepala dibagian seksi. KPP2 juga merupakan kepala seksi suatu bidang yang cukup strategis karena berkaitan dengan penentuan anggaran program KPP Pratama Surakarta sehingga data keuangan yang peneliti peroleh valid. Tidak kalah pentingnya, informan KPP3 yang merupakan kepala seksi memiliki informasi yang berkaitan dengan pelayanan dan beragam program yang ada pada KPP Pratama Surakarta dalam meningkatkan pengguna $e$ filing. Kemudian yang terakhir adalah KPP4 yang juga menjabat sebagai pelaksana program disalah satu bidang yang berperan untuk keberlangsungan program di lapangan. Kemudian peneliti juga melakukan wawancara dengan wajib pajak untuk memastikan program yang dilakukan oleh 
KPP Pratama Surakarta, wajib pajak bekerja di salah satu perusahaan tekstil di wilayah solo raya. WP1 berprofesi karyawan dan WP2 sebagai komunikator perusahaan dengan instansi pemerintah khususnya perpajakan sedangkan WP3 merupakan salah satu pegawai dari instansi pemerintahan, bea cukai solo. Berikut ini pengkodean dan keterangan untuk memperjelas hasil penulisan:

Tabel 1. Koding Informan

\begin{tabular}{|c|c|c|}
\hline $\begin{array}{c}\text { Singkatan } \\
\text { Nama }\end{array}$ & Kode & Keterangan \\
\hline F & KPP1 & $\begin{array}{c}\text { Key Informan di bidang } \\
\text { PDI }\end{array}$ \\
\hline A & KPP2 & $\begin{array}{c}\text { Key Informan di bidang } \\
\text { Umum }\end{array}$ \\
\hline H & KPP3 & $\begin{array}{c}\text { Key Informan di bidang } \\
\text { Pelayanan }\end{array}$ \\
\hline W & KPP4 & $\begin{array}{c}\text { Key Informan di bidang } \\
\text { Ekstensifikasi }\end{array}$ \\
\hline E & WP1 & $\begin{array}{c}\text { Wajib pajak dari } \\
\text { perusahaan }\end{array}$ \\
\hline U & WP2 & $\begin{array}{c}\text { Wajib pajak dari } \\
\text { perusahaan }\end{array}$ \\
\hline D & WP3 & $\begin{array}{c}\text { Wajib pajak dari Bea Cukai } \\
\text { Solo }\end{array}$ \\
\hline
\end{tabular}

Implementasi strategi oleh KPP Pratama Surakarta dalam meningkatkan pengguna $e$ filing di Kota Surakarta.Penulis menggunakan acuan dari rencana strategis (Renstra) Direktorat Jendral Pajak tahun 2015-2019.

\section{b. Program}

Implementasi strategi dalam pencapaian kepatuhan wajib pajak melalui target $e$-filing di Kota Surakarta ini dapat diketahui melalui program-program yang dijalankan, yang mana program-program ini merupakan turunan dari rencana startegis Direktorat Jendral Pajak. Program-program ini, merupakan inisiatif dari KPP Pratama Surakarta sendiri yang melihat dari rencana strategis Direktorat Jendral Pajak yang salah satunya melakukan migrasi wajib pajak menggunakan e-filing bahwa KPP Pratama Surakarta memiliki program sosialisasi tidak langsung dan sosialisasi langsung. Yang pertama program sosialisasi tidak langsung, ini merupakan salah satu cara yang dilakukan oleh KPP Pratama Surakarta untuk menjangkau wajib pajak yang tersebar di wilayah kota Surakarta. Media yang digunakan seperti iklan di televisi (diambil penuh oleh Direktorat Jendral Pajak pusat), maupun kampanye e-filing lewat radio, memasang iklan di media cetak dan bahkan mencetak beragam brosur, pamflet dan spanduk yang nantinya dipasang di tempat strategis di wilayah kota Surakarta. Dalam melaksanakan program sosialisasi tidak langsung ini, KPP Pratama Surakarta juga berkoordinasi dengan Kanwil DJP Jateng II dan pemerintah kota Surakarta. Koordinasi ini berguna untuk mensukseskan kampanye e-filing supaya informasi bisa disampaikan untuk wajib pajak. KPP Pratama Surakarta berkoordinasi langsung dengan Pemerintah kota Surakarta dalam hal pemasangan spanduk serta berkoordinasi dengan Kanwil DJP Jateng II dalam menyebarkan brosur kampanye e-filing. Dari program sosialisasi tidak langsung yang berisi kampanye tersebut diharapkan oleh KPP Pratama agar kedepannya wajib pajak banyak yang beralih ke sistem $e$-filing.

Kedua adalah sosialisasi secara langsung, yaitu sosialisasi tatap muka dengan wajib pajak yang ini merupakan komunikasi dua arah yang bisa dikatakan sangat efektif untuk mempengaruhi wajib pajak agar segera beralih ke sistem e-filing dalam 
pelaporan SPT tahunan secara online. Program kelas pajak, program ini diadakan oleh KPP Pratama Surakarta ketika batas waktu pelaporan SPT Tahunan hampir mendekati batas akhir, sekitar 4 bulan sebelum berakhir tepatnya. Kelas pajak ini dilakukan di berbagai tempat, bisa dilaksanakan di KPP Pratama Surakarta maupun diluar KPP Pratama Surakarta, seperti instansi maupun perusahaan swasta. Kelas pajak dilakukan guna menginstensifkan sosialisasi secara langsung kepada wajib pajak, karena pada tahun 2016 ini masih merupakan tahap sosialisasi mengingat rilis sistem $e$-filing ini pada tahun 2014.

Dalam pelaksanaan program kelas pajak yang pernah dilakukan di kantor KPP Pratama Surakarta, respon wajib pajak sudah lumayan baik. Terlihat bahwa KPP Pratama Surakarta secara aktif mengundang perwakilan dari instansi atau perusahaan yang memiliki posisi penting atau vital di perusahaan tersebut. Kita ketahui bahwa strategi kelas pajak yang dilakukan oleh KPP Pratama Surakarta ini, sebagai startegi untuk mensukseskan migrasi wajib pajak ke pelaporan SPT melalui e-filing. Banyaknya tamu undangan dari berbagai instansi atau perusahaan tersebut diharapkan oleh KPP Pratama untuk menjelaskan secara berkelanjutan ke instansi atau perusahaan mereka agar mensosialisasikan program $e$ filing ini, agar kedepannya wajib pajak banyak yang beralih ke sistem e-filing. Namun perlu diingat bahwa program kelas pajak ini suatu seminar yang tidak hanya membahas tentang e-filing saja namun semua kegiatan perpajakan. Meski demikian, keberhasilan program kelas pajak ini bergantung pada kesadaran wajib pajak untuk menghadari acara tersebut. Selanjutnya adalah Program Jemput Bola, artinya KPP Pratama Surakarta menerapkan salah satu strategi yang misinya adalah melayani wajib pajak khususnya yang berprofesi sebagai karyawan atau pegawai untuk mempermudah kegiatannya dalam mengisi Surat pemberitahuan secara online/ e-filing dengan cara KPP Pratama Surakarta mengunjungi instansi maupun perusahaan untuk melakukan acara mengisi e-filing bersama, yang mana sebelumnya telah dibuat jadwal lebih dahulu antara instansi dengan KPP Pratama Surakarta. Dalam hal ini KPP Pratama Surakarta bisa dikatakan responsif menanggapi permintaan yang disampaikan oleh instansi atau perusahaan tersebut. Program ini dilakukan karena mengingat wajib pajak yang berjumlah sangat banyak dan masih banyaknya wajib pajak yang belum memahami secara detail apa itu e-filing, maka peran aktif KPP Pratama Surakarta ini menjadi sangat penting. Kita ketahui bahwa strategi jemput bola ke wilayah kantong-kantong wajib pajak tersebut yang dilakukan oleh KPP Pratama sangat mendukung dalam pencapian target kepatuhan wajib pajak yang melaporkan SPT, dengan salah satu caranya mengajak wajib pajak beralih dari cara lapor manual menjadi lapor SPT online atau biasa disebut $e$-filing. Program jemput bola ini merupakan salah satu terobosan yang dilakukan oleh KPP Pratama yang mana menempatkan posisinya secara aktif untuk menjangkau wajib pajak yang benarbenar serius untuk melakukan pengisian SPT melalui e-filing. Jemput bola yang 
dilakukan oleh KPP Pratama Surakarta ini, bisa terlaksana apabila terjadi kesepakatan antar instansi maupun perusahaan dengan KPP Pratama itu sendiri, penentuan jadwal dan tempat merupakan hal penting dalam keberhasilan program jemput bola ini. Pihak KPP Pratama Surakarta sendiri selalu mengusahakan agar program ini berjalan dengan lancar, bahkan diluar jam kerja atau malam hari.

\section{c. Anggaran}

Anggaran hanya menyangkut keperluan untuk pelaksanaan kegiatan SPT Tahunan dalam hal ini termasuk penyuluhan tentang kampanye $e$-filing maupun kampanye melalui media.Anggaran itu bisa diubah sesuai kebutuhan KPP Pratama Surakarta karena memang diakui setiap anggaran tidak mungkin sesuai dengan angka yang telah ditetapkan sebelumnya. Bisa dilihat bahwa anggaran bisa switch change dalam pos anggaran, yang mana perubahan pos anggaran ini dilegalkan dengan syarat tidak merubah pos modal, dan hanya bisa merubah yang ada pada pos anggaran sejenis. Anggaran sebelumnya ditentukan oleh Direktorat Jendral Pajak Pusat kemudian dialokasikan ke KPP Pratama, bahkan secara legal bisa dilakukan revisi untuk penyesuaian kegiatan di KPP Pratama.

\section{d. Prosedur}

Prosedur dilakukan dalam melakukan suatu pekerjaan agar terciptanya hasil yang diinginkan. Dalam hal ini, setiap program yang ada seperti sosialisasi tidak langsung maupun langsung telah disusun secara jelas dan telah dibuat satuan tugas (satgas). Didukung oleh adanya satuan tugas yang ada di KPP Pratama Surakarta.Anggota satgas terdiri dari internal KPP Pratama Surakarta, tanpa melibatkan pihak luar karena data $e$-filing wajib pajak bersifat rahasia, maka dari itu tidak memungkinkan adanya kesempatan bagi pihak diluar KPP Pratama Surakarta untuk ikut campur.Dalam pelaksanaan program jemput bola maupun kelas pajak yang diadakan di luar instansi KPP Pratama Surakarta, telah disusun jadwalnya sesuai dengan permintaan dan kesepakatan antara KPP Pratama Surakarta dengan instansi yang dituju.

Saat pelaksanaan di lapangan, hanya ada sekitar 3-4 pegawai yang terjun mengisi penyuluhan karena dalam waktu satu hari bisa 3 sampai 4 penyuluhan di tempat yang berbeda. Perlu adanya keseimbangan pembagian tugas, karena sepenuhnya penunjukan satgas ini wewenang dari kepala KPP Pratama Surakarta, oleh karena itu perlu memilih petugas secara cermat dari ketersediaan pegawai KPP Pratama Surakarta yang berjumlah sekitar 110 orang, harus tepat membagi jam penyuluhan, jumlah pegawai, dan penyesuaian tempat penyuluhan atau kelas pajak tersebut. Musim lapor melalui e-filing bisa dilakukan dari bulan januari sampai maret, tetapi KPP Pratama Surakarta sudah bergerak dari bulan Desember tahun sebelumnya untuk melakukan sosialisasi melalui kelas pajak tersebut, itu saja menurut KPP Pratama Surakarta belum bisa maksimal karena keterbatasan pegawai atau sumber daya manusia-nya. Sedangkan untuk melakukan kampanye KPP Pratama Surakarta melibatkan instansi perpajakan yang lebih tinggi yaitu pihak yang berkaitan dengan 
aktifitas perpajakan seperti Kanwil dan DJP Pusat yang berada 2 tingkat diatas KPP Pratama. Dari informasi tersebut bisa dilihat bagaimana penyusunan prosedur dan anggota satgas yang matang dari KPP Pratama Surakarta itu sendiri, mulai dari penjadwalan yang terstruktur dan optimalisasi sumber daya pegawai yang ada di KPP Pratama Surakarta.

\section{e. Sosial}

Aspek sosial dalam hal kepekaan KPP Pratama Surakarta dalam mencoba menyelaraskan program e-filing dengan gap yang ada, gap disini terlihat ketika adanya kesenjangan teknologi antar wajib pajak.wajib pajak tidak semuanya memiliki gadget untuk mengakses website e-filing. Disini KPP Pratama Surakarta sadar akan hal itu, jika masalah itu dibiarkan yang ada hanyalah wajib pajak tidak akan patuh untuk lapor SPT tahunan. Oleh sebab itu KPP Pratama Surakarta menyediakan sekitar 20 personal computer dan menyediakan pegawai untuk membimbing wajib pajak untuk mengisi data e-filing. Dengan kata lain, KPP Pratama Surakarta sangat peka terhadap apa itu kesenjangan teknologi dan tanggap terhadap masalah wajib pajak dalam pengisian $e$-filing.

Sebelumnya pada tahun 2015 yang lalu KPP Pratama Surakarta hanya menggunakan sekitar 8-10 komputer untuk melayani wajib pajak pengguna $e$-filing, tetapi saat ini tahun 2016 telah terkonfirmasi bahwa KPP Pratama Surakarta meningkatkan menjadi sekitar 20 komputer untuk melayani wajib pajak pengguna e-filing yang mana 20 komputer tersebut tersebar di depan (front office) bagian kanan dan kiri serta sebagian ada di aula jika membeludaknya wajib pajak ketika menjelang batas akhir pelaporan SPT tahunan.

\section{E. Kesimpulan}

Dari penelitian yang dilakukan dilapangan menunjukkan Implementasi Strategi KPP Pratama Surakarta dalam meningkatkan pengguna e-filing di kota Surakarta, maka dapat ditarik kesimpulan secara garis besar bahwa implementasi strategi yang dalam meningkatkan pengguna e-filing sudah berjalan dengan baik, dari program, anggaran, prosedur dan aspek sosial. Hal ini dapat diketahui dari program dan kegiatan yang menunjang pencapain target pengguna e-filing tersebut dapat direalisasikan dengan baik, kegiatan program jemput bola, kelas pajak, sosialisasi, kampanye e-filing. Anggaran yang bisa disesuaikan oleh KPP Pratama Surakarta dengan cara switch change, mampu mengelola anggaran supaya disesuaikan dengan kebutuhan instansi. Prosedur yang memfokuskan optimalisasi satgas yang bekerja sesuai perintah kepala KPP Pratama Surakarta mampu melakukan program dilapangan dengan koordinasi yang baik.Serta penyediaan fasilitas pelayanan yang mumpuni untuk melayani wajib pajak yang mengisi e-filing di KPP Pratama Surakarta secara langsung.

\section{Daftar Pustaka}

Al-Shafi, Shafi Homoud. 2009. Factors Affecting E-Government Implementation and Adoption in The State Of Qatar. PhD Thesis. Brunel University of West London, UK. 
Andrianto, Nico. 2007. Good EGovernment: Transparansi dan Akuntabilitas Publik Melalui EGovernment. Malang: Bayumedia

Anindya, R. 2013. Startegi Pelayanan Publik Dalam Meningkatkan Kepatuhan Wajib Pajak. Jurnal Kebijakan dan Manajemen Publik , Universitas Airlangga.

Anna Che Azmi dan Ng Lee Bee. 2010.The Acceptance of the e-Filling System by Malaysian Taxpayers: A Simplified Model. Electronic Journal of e- Government Volume 8 Issue 1 2010, (pp13 - 22). Academic Conferences Ltd.

Ambali, A. 2009.E-Government Policy: Ground Issues in E-filing System. European Journal of Social Sciences - Volume 11, Number 2.University Technology Mara, Malaysia.

Dewi ,A. 2009. Manajemen Keuangan Perusahaan. Ghalia Indonesia, Jakarta.

Fasmi, L. 2012. Pengaruh Modernisasi Sistem Administrasi Perpajakan Terhadap Tingkat Kepatuhan Pengusaha Kena Pajak di Kantor Pelayanan Pajak (KPP)

Pratama Padang. Universitas Andalas.

Indrajit, Richardus Eko. 2002. Electronic Government: Strategi Pembangunan dan Pengembangan Sistem

$\begin{array}{lrr}\text { Pelayanan } & \text { Publik } & \text { Berbasis } \\ \text { Teknologi } & \text { Digital. } & \text { Yogyakarta: } \\ \text { Andi } & & \end{array}$

Ivonne,R. 2012. Implementasi Elektronik Surat Pemberitahuan Pajak Pertambahan Nilai 1111 Versi 1.5 di
Kantor Pelayanan Pajak Pratama Sidoarjo Utara.Jurnal Ilmu Administrasi Negara. Universitas Negeri Surabaya.

James Abiola dan Moses Asiweh. 2012. Impact of Tax Administration on Government Revenue in a Developing Economy - A Case Study of Nigeria. International Journal of Business and Social Science Vol. 3 No. 8. Leicester Business School De Montfort University, UK.

Manurung, S. 2013. Kompleksitas Kepatuhan Pajak. www.pajak.go.id diakses pada 25 Maret 2016.

Nita Rysaka, Choirul Saleh dan Stefanus Pani Rengu. 2013.Penerapan Sistem Elektronik Dalam Pelayanan Perpajakan (Studi pada Kantor Pelayanan Pajak Pratama Malang Utara). Jurnal Ilmu Administrasi Negara. Universitas Brawijaya Malang.

Nurcholis, H. 2007. Teori dan Praktik Pemerintahan dan Otonomi Daerah. Grasindo, Jakarta.

Rahardjo, Budi. 2001. Membangun EGovernment.

PPAU

Mikroelektronika ITB

Rahman, A. 2010. Panduan Pelaksanaan Administrasi Perpajakan Untuk Karyawan, Pelaku Bisnis dan Perusahaan. Nuansa, Bandung.

Riviyastuti, A. 15 Maret 2016. SPT Tahunan Tingkat Kepatuhan Wajib Pajak Ditarget 75\%..www.koransolo.co diakses pada 26 Maret 2016.

Riviyastuti ,A. 18 Maret 2016. 27.000 WP $O P$ di Solo Ditarget Gunakan E- 
filling. www.solopos.com diakses pada 26 Maret 2016.

Ken, N. 09 Mei 2016.Pelaporan SPT Naik 13,1 Persen Tahun Ini. www.jawapos.com diakses pada 12 mei 2016.

Rokhman, Ali. 2008. Potret dan Hambatan E-Government Indonesia: Inovasi Online. Edisi Vol.11/XX, Juli 2008

Sisilia Abdurrohman, Tjahjanulin Domai dan Muhammad Shobaruddin. (2014). Implementasi

Program E-filing Dalam Upaya Peningkatan Kepatuhan Wajib

Pajak Orang Pribadi (Studi pada Kantor Pelayanan Pajak Pratama Bojonegoro). Jurnal Ilmu Administrasi Negara. Universitas Brawijaya Malang.

Titis Bonang dan Arifin Sabeni. 2013. Faktor-Faktor Yang Mempengaruhi Pergantian KAP. Jurnal akuntansi, Vol.2 No.3,hal. 1-12, Universitas Diponegoro 
Spirit Publik Volume 12, Nomor 2, Oktober 2017

Halaman 1-13

P-ISSN. 1907-0489 E-ISSN 2580-3875 